\title{
Acute leukemia in sickle cell disease patients in a tertiary health facility in Nigeria: a case series
}

\author{
Oladapo W Aworanti ${ }^{1}$, Foluke A Fasola 2 , Taiwo R Kotila ${ }^{2,}$, John A Olaniyi ${ }^{2}$, Biobele J Brown ${ }^{2}$
}

\author{
1. Haematology Department, Central Laboratory, Synlab Nigeria Limited, Lagos. \\ 2. Department of Haematology, College of Medicine, University of Ibadan, Nigeria.
}

\begin{abstract}
Background and objectives: Sickle cell disease(SCD) is a disorder of red cells resulting from the co-inheritance of haemoglobin S (HbS) with another abnormal haemoglobin. The diagnosis of acute leukaemia is uncommon in our patients with sickle cell disease more so the patients have high morbidity and mortality due to the sickling process. Acute leukemia is a malignant clonal disorder of haemopoietic precursor cells resulting in accumulation of immature blood cells in the bone marrow and blood.The objective of the case series was to highlight the challenges of diagnosis and management of SCD patients with acute leukaemia, the importance of peripheral blood film review and propound a possible risk factor.

Methods: Records of 58 patients diagnosed and managed for acute leukaemia over a 7 year period at the University College Hospital, Ibadan were reviewed. The diagnosis of acute leukaemia was based on clinical features in addition to peripheral and bone marrow smears findings. Microsoft excel version 2013 was used for statistical analysis.

Results: Five (8.6\%) of the patients with acute leukaemia also had sickle cell disease: 3 males and 2 females were described. Recurrent fever and anaemia were the most consistent presenting features in the patients. All the patients were not on any routine medications meant for SCD patients and had poor history of clinic attendance prior to the diagnosis of acute leukaemia. The diagnosis of acute leukaemia was not made until the patients were seen by a haematologist. The principal tool of diagnosis in all the patients was peripheral blood film review. Two patients were discharged against medical advice.The treatment period ranged between one month and one year in the remaining three patients.

Conclusion: SCD patients are not exempted from developing acute leukaemias and the diagnoses of the two conditions overwhelms the social and economic support of patients and care givers. The study also underscores the relevance of high level of suspicion and prompt review of peripheral blood film of SCD patients particularly when patients present with unremitting symptoms associated with anaemia and fever.
\end{abstract}

Keywords: Acute leukaemia, sickle cell disease, anaemia.

DOI: https://dx.doi.org/10.4314/ahs.v20i3.36

Cite as: Aworanti OW, Fasola FA, Kotila TR, Olaniyi JA, Brown BJ. Acute leukemia in sickle cell disease patients in a tertiary health facility in Nigeria: a case series. Afri Health Sci. 2020;20(3): 1304-1312. bttps:/ / dx.doi.org/10.4314/ abs.v20i3.36

\section{Introduction}

Sickle cell disease is a blood disorder resulting from the inheritance of two abnormal alleles controlling the formation of the beta globin chains of haemoglobin with at least one of which is the sickle gene, for

\section{Corresponding author: \\ Fasola FA, \\ Department of Haematology, \\ College of Medicine, \\ University of Ibadan, Nigeria. \\ Tel: +2348033375785 \\ Email: folukefasola@yahoo.com}

example; Hb-SS, Hb-SC and HbS $\beta$ thal. The mutation in the sickle gene is asingle base substitution (A-T) in the first exon of the human beta globin genewhich results in a structural variant of adult haemoglobin ( $\mathrm{HbA})$ called sickle haemoglobin (HbS) ${ }^{1}$. Patients who inherit the sickle haemoglobin in either the homozygote or compound heterozygote state have lifelong anaemia and intermittent vaso-occlusion. The sickle haemoglobin polymerizes at low oxygen tension resulting in sickle red cells. Sickle red cells have shorter life span than normal red cells.Morbidity and mortality due to the complications of anaemia and vaso-occlusion in these patients used to be high such that the development of haematological malignancy was thought to be rare in patients. ${ }^{2}$ 
A study in England reported a higher cancer incidence among SCD patients compared to other patients. ${ }^{3}$ Another study from California reported that SCD patients had over a twofold increased risk for leukaemia ${ }^{4}$. Acute leukaemias are malignant clonal diseases in which there is unregulated proliferation, expansion and accumulation of immature leukocytes in bone marrow and blood with suppression of normal haemopoiesis.

The accumulation of multiple genetic abnormalities over years, due to a high degree of proliferative activity of BM cells in sickle cell disease may increase the risk for haematological cancer ${ }^{5}$. Acute leukaemias are classified according to lineage into lymphoid, myeloid and occasionally mixed leukaemia. The cells have maturation arrest and defective programmed cell death with uncontrolled rapid proliferation of blast cells resulting in the accumulation of the blast cells in the bone marrow, the blood and frequently the lymph nodes, the spleen and the liver ${ }^{6}$. The underlying mechanism of the maturation arrest and uncontrolled proliferation is the activation or inactivation of genes through chromosomal translocations and other genetic and/or epigenetic abnormalities ${ }^{7}$. It was suggested that mutations due to high cellular turnover and chronic inflammation in leukemic pathogenesis may be high in sickle cell disease ${ }^{8}$.The appearance of a leukaemic process in a patient with sickle cell disease may confound the presentation and compound the management of the patient. Furthermore, the diagnosis of acute leukaemia in SCD patients could be devastating for patients and care giver. Hence the objective of this study, is to report the clinical and haematological profile of sickle cell disease patients that were diagnosed with acute leukaemia in our institution in order to increase suspicion of the diagnosisby clinician, demonstrate the importance of peripheral blood film review and present the challenges encountered in the management of the patients. An attempt will also be made to propound the risk factors for the development of acute leukaemia in these patients.

\section{Methods}

The hospital records of 58 patients treated for acute leukaemia at the University College Hospital, Ibadan between January 2011 and December 2017 were reviewed.The patients with sickle cell disease diagnosed with acute leukaemia were identified and their hard copy case notes were retrieved for detailed information on the presentation and management. The hospital is a tertiary center with 1000 beds. The hospital offers services in various sub-specialties of Surgery, Medicine, Paediatrics, Obstetrics and Gynaecology, Radio- diagnosis, Dentistry, Psychiatry, General Practice and Community Medicine. The pathology services include Morbid Anatomy/Histopathology, Medical Microbiology, Chemical Pathology and Haematology. The diagnosis of patients with acute leukaemia in the hospital is based on clinical and laboratory features, confirmed with the review of peripheral blood film and of bone marrow aspiration smear stained with May Grunwald stain. Flow cytometry and molecular technology are not available. Management of patients include support with blood and blood product and cytotoxic therapy. Diagnosis of sickle cell disease was based on haemoglobin electrophoresis carried out at $\mathrm{pH}$ 8.6. Information retrieved included clinical and laboratory features at presentation with emphasis on full blood count (FBC) and outcome ofanagement. The patients were treated based on the type of acute leukaemia that was diagnosed. Microsoft excel version 2013 was employed to carry out the statistical analysis. Frequency, mean, and standard deviation were determined for variables.

\section{Case presentation}

The cases were 5 with male: female ratio of 3:2.The median age of the patients was 15 years with a range of 3 to 21 years. All the patients were students and still dependent on their parents for social and economic needs

\section{Case one}

Fifteen-year-old male patient, who was diagnosed with sickle anaemia at 2 years, was referred to our clinic with two weeks' history of fever, two days history of passage of deep amber coloured urine and a day history of bone pain. Fever was high grade and continuous associated with headache, dysuria, lower abdominal painand deepening jaundice. There was no cough, chest pain, difficulty with breathing, dizzy or fainting spell. Bone pain involved the knees and ankles bilaterally. Pain score at presentation was $8 / 10$.

Past medical history revealed that he had been transfused once in his life time at 5 years. He had not been regular with both clinics follow up and routine medications. His steady state PCV was $25 \%$, frequency of bone pain crisis was 2 per year but in the preceding 4 months, the frequency increased to once per month. No history of stroke, leg ulcer, priapism or any other complication of sickle cell disease.

Examination at presentation showed a chronically ill looking young man, severely pale, febrile ( $\mathrm{T}-39.50 \mathrm{C})$; icteric, dehydrated, generalized lymphadenopathy; bilateral submandibular, submental, cervical, axillary and 
inguinal regions. Lymph nodes were discrete, the largest ones were in the axillary region and measured $3 \times 4 x 4 c m$. The pulse rate (PR)was $120 / \mathrm{min}$, blood pressure (BP) was $100 / 50 \mathrm{mmHg}$ and $1^{\text {st }}$ and $2^{\text {nd }}$ heart sounds with tachycardia were heard. The respiratory rate (RR)was $28 / \mathrm{min}$, vesicular breath sound was heard and oxygen saturation (SPO2) was $98 \%$ at room air. Abdominal examination showed a full abdomen,which movedwith respiration. There was no area of tenderness. The liver was firm, non-tender and palpably enlarged, $6 \mathrm{~cm}$ below the right coastal margin. The spleen was also, firm, non-tender and palpably enlarged $5 \mathrm{~cm}$ below the left coastal margin. Musculoskeletal examination showed moderate tenderness in both knees and ankles;however, there was no swelling or differential warmth. Full blood count (FBC) was as shown in Table 2. Review of PBF showed red cell features including sickled erythrocytes, severe microcytosis, hypochromia and target cells with anisopoikilocytosis. There was hyperleucocytosis with numerous small to intermediate sized mononuclear cells, with thin rim of agranular cytoplasm, regular nuclear outline and open chromatin pattern; some of the mononuclear cells have moderately abundant cytoplasm with occasional granules and conspicuous nucleoli. These cells were considered to be blasts of both myeloid and lymphoid origin. There was severe thrombocytopaenia.

Bone marrow aspiration cytology showed an hyper cellular marrow with fat: cell ratio of 10:90, myeloid: erythroid ratio of 20:1. Erythroid activity was depressed and erythropoiesis was micro-normoblastic. Myeloid precursor cells were increased with maturation arrest at myeloblast and monoblast stages. There was florid sheets of lymphoblasts on the bone marrow film. Megakaryocytes were not seen. Impression was mixed phenotype acute leukaemia

Table 1: Case summary showing the socio-demographics and clinical presentations of the patients

\begin{tabular}{|c|c|c|c|c|c|}
\hline Demography & Case 1 & Case 2 & Case 3 & Case 4 & Case 5 \\
\hline Sex & Male & Female & Male & Male & Female \\
\hline Age & $15 \mathrm{yr}$ & $21 \mathrm{yr}$ & $15 \mathrm{yr}$ & $3 y r$ & $15 \mathrm{yr}$ \\
\hline Education & Secondary & Tertiary & Secondary & Preschool & Secondary \\
\hline $\mathrm{Hb}$ Elect & $\mathrm{HbS}$ & $\mathrm{HbS}$ & $\mathrm{HbS}+\mathrm{C}$ & $\mathrm{HbS}+\mathrm{C}$ & $\mathrm{HbS}$ \\
\hline $\begin{array}{l}\text { Regular Hospital } \\
\text { follow up }\end{array}$ & No & No & No & No & Yes \\
\hline $\begin{array}{l}\text { Adherence to } \\
\text { routine } \\
\text { medications }\end{array}$ & No & No & No & No & Yes \\
\hline $\begin{array}{l}\text { Recurrent } \\
\text { anaemia }\end{array}$ & + & + & + & + & + \\
\hline Recurrent fever & + & + & + & + & + \\
\hline Hepatomegaly & + & + & - & + & + \\
\hline Splenomegaly & + & - & - & + & - \\
\hline Lymphadenopathy & + & + & - & + & + \\
\hline
\end{tabular}


Urinalysis showed $2+$ of protein and urobilinogen. Results of electrolytes, urea and creatinine and Liver function test were as shown in Table 2. Abdominal USS showed hepatosplenomegaly with liver span of $21 \mathrm{~cm}$ and splenic span of $15 \mathrm{~cm}$. Both kidneys were enlarged with bilateral grade 3 renal parenchymal disease. The patient had 6 units of packed red cells and 2 units of available platelet concentrate transfusion in preparation for commencement of chemotherapy. Patient however died before the chemotherapy was commenced.

Table 2: Haematologicaland Biochemical Parameters of the patients at Presentation

\begin{tabular}{|l|l|l|l|l|l|}
\hline Parameters & Case 1 & Case 2 & Case 3 & Case 4 & Case 5 \\
\hline HCT & $17 \%$ & $18 \%$ & $22 \%$ & $8 \%$ & $13 \%$ \\
\hline WBC & 127,300 & 148,000 & 180,600 & 176,000 & 209,700 \\
\hline Blast percentage(\%) & 80 & 85 & 70 & 70 & 60 \\
\hline Diagnosis & $\begin{array}{l}\text { Acute } \\
\text { Leukaemia- } \\
\text { Mixed } \\
\text { lineage }\end{array}$ & ALL & AML & AML & AML \\
\hline Platelet & 31,000 & 28,000 & 70,000 & 25,000 & 68,000 \\
\hline Sodium & 129 & 135 & 137 & 130 & 140 \\
\hline Potassium & 4.6 & 4.0 & 4.2 & 3.8 & 4.5 \\
\hline Chloride & 103 & 98 & 100 & 102 & 105 \\
\hline Bicarbonate & 18 & 23 & 22 & 20 & 27 \\
\hline Urea & 95 & 18 & 17 & 22 & 32 \\
\hline Creatinine & 1.2 & 0.6 & 0.4 & 0.8 & 0.5 \\
\hline Total Bilirubin & 3.2 & 0.8 & 2.2 & 1.5 & 1.8 \\
\hline Direct Bilirubin & 3.0 & 0.4 & 0.6 & 0.4 & 0.6 \\
\hline ALT & 27 & 89 & 22 & 24 & 32 \\
\hline AST & 152 & 73 & 18 & 28 & 22 \\
\hline ALP & 780 & 39 & 40 & 78 & 68 \\
\hline Total Protein & 6.2 & 8.6 & 7.2 & 8.0 & 6.8 \\
\hline Albumin & 2.4 & 4.0 & 4.4 & 4.6 & 4.2 \\
\hline
\end{tabular}

\section{Case 2}

She was a 21 year old $\mathrm{HbS}$ patient diagnosed at 4 years of age that was referred from a private health facility with 3 weeks history of high grade and unremitting fever and headache. At referral hospital, patient was transfused with a unit of blood on account of anaemia and subsequently developed thrombophlebitis at the site of cannulation. Patient had not been on either routine medications or follow up at SCD clinic. Frequency of bone pain crisis was at least once in a year. Steady state haematocrit was not known. There was no significant past medical history.

General examination at presentation showed a young lady who was acutely ill looking, moderately pale, icteric, febrile $\left(\mathrm{T}-38.6^{\circ} \mathrm{C}\right)$, acyanosed, fairly hydrated and had generalized lymphadenopathy less than $2 \mathrm{~cm}$ in diameter involving the cervical, axillary and inguinal regions. There was no pedal oedema. Cardiovascular examination revealed a pulse rate of $104 / \mathrm{min}$, blood pressure of $110 / 80 \mathrm{mmHg}, 1^{\text {st }}$ and $2^{\text {nd }}$ heart soundswith $3 \mathrm{rd}$ heart sound.

Examination of the chest showed a respiratory rate of $24 / \mathrm{min}$ with vesicular breath sounds.

Abdomen was flat and moved with respiration.There was no area of tenderness, but liver was palpated $4 \mathrm{~cm}$ below right coastal margin.FBC done at presentation was as shown in Table 2.

Peripheral blood film reviewed showed severe microcytosis and hypochromia, numerous target cells, irreversible sickle cell of about $4 \%$. The total white cell count was estimated to be 148,000 with lymphoblast constituting about $85 \%$ and platelet count less than 36,000.

Electrolytes, Urea, creatinine and liver function test results were as shown in Table 2. Other investigations done include: Chest x-ray which was essentially normal. Abdominopelvic ultrasound scan was also essentially normal with liver and spleen within normal limits. Based on the abundant lymphoblasts and thrombocytopenia 
on peripheral film, the diagnosis of acute lymphoblastic leukaemia was sustained despite that bone marrow aspiration was not done due to unavailability of funds. On the $5^{\text {th }}$ day of admission, she was discharged against medical advice despite counseling on the nature of the disease and treatment.

\section{Case 3}

This is a 15 -year-old secondary school HbS $+\mathrm{C}$ patient diagnosed in childhood who was referred to continue treatment for Acute Myeloid Leukaemia- (AML) M4 in our institution because of proximity to family. He initially presented at the tertiary medical center with a month history of high grade fever, bilateral eyelid swelling and anaemia with a haematocrit of $10 \%$. Based on FBC, peripheral blood film and bone marrow findings, a diagnosis of AML was made and she was commenced on chemotherapy: Doxorubicin and cytosine arabinoside (DA). Post chemotherapy bone marrow aspiration for cytology done after the $2^{\text {nd }}$ and $3^{\text {rd }}$ cycle of chemotherapy showed myeloblast percentage of $10 \% \& 2 \%$ respectively. Chemotherapy was then discontinued. Four months after, patient presented to our health care facility on account of recurrent bilateral eyelid swelling, proptosis and associated blurring of vision. No associated fever, headache, bone pain, cough, chest pain or difficulty with breathing

Past medical history showed that the patient had not been regular with routine medications and hospital follow up. Steady state PCV was not known. Frequency of bone pain crisis was once in $2-3$ years. However, frequency of bone pain crisis increased when the illness started. During admission in our facility, the patient had 2 episodes of bone pain crisis.

Examination at presentation showed an acutely ill looking young man, afebrile, mildly pale, no significant peripheral lymphadenopathy, bilateral periorbital swelling. There was also tenderness over the eyelids, and ecchymosis of the right eyelid. Visual activity was $6 / 60$ in the right eye, $6 / 18$ in the left eye. Pulse rate was $84 /$ minute, the $\mathrm{BP}$ was $80 / 60 \mathrm{~mm} \mathrm{Hg}$, with normal $1^{\text {st }}$ and $2^{\text {nd }}$ heart sounds. The chest was found to be clinically normal: RR was 20 breaths with vesicular breath sounds. Abdominal examination showed a flat abdomen with no area of tenderness and no palpable organs. FBC done at presentation is shown in Table 2. Electrolytes, urea, creatinine and liver function tests results are shown in Table 2. Other investigations included:

Review of peripheral blood film which showed severe microcytosis, hypochromia, numerous target cells. The white cell was estimated to be about $160,000 / \mathrm{mm}^{3}$ with the blast constituting about $70 \%$ and mild thrombocytopaenia.Bone marrow aspiration film was consistent with AML-M4.

Due to ongoing industrial action and unavailability of blood products, the patient was commenced on SC cytosinearabinoside at $70 \mathrm{mg} 12$ hourly for one week. By the $5^{\text {th }}$ day of cytosine arabinoside, orbital swelling had completely resolved and visual acuity in both eyes became $6 / 6$, white cell count also reduced to $17,900 / \mathrm{mm}^{2}$ from $180,000 / \mathrm{mm}^{2}$

On the $16^{\text {th }}$ day of admission, industrial action was called off; he was then commenced on $1^{\text {st }}$ cycle, $2^{\text {nd }}$ course of re -induction of remission with Doxorubicin and cytosine arabinoside (DA). The patient had a cardiac ECHO done which showed aortic annulus sclerosis with mild pulmonary regurgitation and mild pericardial effusion. Doxorubicin was substituted with epirubicin in the $2^{\text {nd }}$ cycle of the $2^{\text {nd }}$ course of re-induction of remission. The $2^{\text {nd }}$ cycle with epirubicin was particularly complicated by thrombocytopenic bleeding, severe neutropenic fever and upper gastrointestinal bleeding. He spent about two and a half months on this admission, during which he was co-managed with the cardiologist, gastroenterologist, ophthalmologist and medical microbiologist. He was also transfused with nine units of fresh whole blood and 12 units of random donor platelet concentrate. He also had SC Granulocyte colony stimulating factor(GCSF) during the $2^{\text {nd }}$ cycle of chemotherapy. The father of patient refused further chemotherapy therefore consolidation chemotherapy could not be instituted. He was discharged in second remission with a bone marrow blast of $<5 \%$. Attempts were made to get haemopoietic stem cell transplantation done or registered in a clinical trial outside Nigeria, but all attempts proved abortive. He re-presented four weeks after discharge with fever, difficulty with breathing and died before any medical intervention could be carried out.

\section{Case 4}

This was a 3 year old $\mathrm{HbS}+\mathrm{C}$ patient who presented with 3 months history of swollen left thigh and two months history of recurrent fever and anaemia. Pain and swelling developed in the left thigh following a fall from a chair. About one month after the fall, he was noticed to be having high grade continuous fever with features suggestive of anemia-generalized weakness, headache and dizzy spells.

He initially presented at a nursing home where an X-ray showed a fracture of the distal left femur. Thereafter, he was managed by a traditional bone setter. 
After spending one month in the bone setting home with no improvement, he presented at our hospital with high grade fever and haematocrit of $12 \%$. He was then urgently transfused with packed cells, received intravenous antibiotics, antimalarials and a back slab for the fracture. Fever resolved with drugs. Two weeks later, he developed high grade fever and PCV dropped to $10 \%$. He was re-commenced on intravenous antibiotics and transfused with 3 units of packed cells. PCV two days after transfusion was $16 \%$, which dropped to $8 \%$ within another 48 hours.

There was no headache, neck stiffness, cough, chest pain or difficulty with breathing. Diagnosis of $\mathrm{HbS}+\mathrm{C}$ was made from blood sample collected at presentation in this illness. Steady state PCV was not known and the patient had not been on any routine medication though patient had been admitted two years before this illness for fever and bone pain. Examination at this presentation revealed a young boy, severely pale, anicteric, febrile $\left(\mathrm{T}-39.2^{\circ} \mathrm{C}\right)$, fair hydration status, back slab on the left lower limb, generalized lymphadenopathy involving the submandibular, occipital, cervical, axillary, epitrochlear and inguinal lymph nodes. They were non-tender, discrete, mobile, with the largest measuring $4 \times 4 \times 4 \mathrm{~cm}$ in the right axilla. Cardiovascular system examination revealed a PR of $120 /$ minute, BP of $80 / 60 \mathrm{~mm} \mathrm{Hg}$ and normal $1^{\text {st }}$ and $2^{\text {nd }}$ heart sounds.

Chest examination showed a RR of $40 / \mathrm{min}$ with vesicular breath sounds. Further examination revealed a flat abdomen, moving with respiration with no area of tenderness; there was hepatosplenomegaly of $10 \mathrm{~cm}$ each below right and left coastal margins respectively. The following further investigations were carried out:

FBC at presentation is shown in Table 2. Repeat FBC after ten days: PCV $-8 \%$, WBC $-176,600 \mathrm{~N}-02 \%$, $\mathrm{L}-96 \%, \mathrm{M}-02 \%$ platelets- $25,000 / \mathrm{mm} 2$. Peripheral blood film review showed severe microcytosis, hypochromia, irreversible sickle cell of $6 \%$, target cells with anisopoikilocytosis in the red cell series. There was hyper-leucocytosis consisting of numerous intermediate sized mononuclear cells, with granular cytoplasm and the nuclei had open chromatin pattern, these were considered to be myeloblasts and constituted about $70 \%$ of total white cell count. There was severe thrombocytopaenia. These features were consistent with acute myeloid leukaemia. Urinalysis showed blood 1+ and protein $1+$. Electrolyte, urea and creatinine results are shown in Table 2. Retroviral screening test for HIV was non-reactive.
Bone marrow aspiration could not be carried out due to lack of funds however the diagnosis was upheld because of the clinical features and blood film assessment. Patient was discharged against medical advice due to lack of financial support.

\section{Case 5}

A 15 year old known HbS who has had a mild clinical course, was referred by the Paediatric Haematology unit of the hospital on account of recurrent blood transfusion (four units of blood in five admissions) over a three months period. She was referred with a raised white cell count, neutropenia and thrombocytopaenia. At the time of first evaluation, a diagnosis of severe megaloblasic crisis with dysplastic changes in the myeloid and lymphoid series was made. She was commenced on triple folate and IM cyanocobalamin for two weeks

However, about six days after commencement of treatment for megaloblastic crisis, she was admitted because of fever, headache and multiple swellings in the leg, left groin and back. The fever was high grade, intermittent and associated with chills and rigors. The swellings were multiple, diffuse and painful. There was mild jaundice, no associated loss of weight, no drenching night sweats and urine was normal colour.

Examination revealed an acutely ill girl, febrile(T-39.50C), severely pale, anicteric, tender left femoral matted inguinal lymphadenopathy measuring $3 \times 3 \times 3 \mathrm{~cm}$. There were no petechiae or ecchymotic patches. She was mildly dyspnoiec with a respiratory rate of 32 breaths per minute and nasal flaring but the breath sounds were vesicular. The patient had a pulse rate of 100 beats per minute, blood pressure of $100 / 60 \mathrm{mmHg}$ and $1^{\text {st }}$ and $2^{\text {nd }}$ heart sounds with systolic murmur. The liver was enlarged $2 \mathrm{~cm}$ below the right coastal margin. The spleen was not enlarged. The following investigations were carried out:

Complete blood countwas as shown in Table 2. The peripheral blood film and bone marrow cytology review were in keeping with AML-M5. Electrolytes, urea and creatinine result is shown in Table 2. She was commenced on subcutaneous cytosine arabinoside $12.5 \mathrm{mg}$ 12 hourly and had six units of packed cells and 10 units of random platelet concentrates transfused over 10 dys. Her clinical condition worsened with development of bilateral conjunctival haemorrhage, bilateral pitting pedal oedema, increasing hepatomegaly (from the initial $2 \mathrm{~cm}$ to $7 \mathrm{~cm}$ ) and hypotension (BP-60/40 mmHg). She later became breathless and desaturating with no breath 
sounds in the right lower lung zone. A pleural fluid tap yielded frank blood, she subsequently had catheter drainage of the right pleural space which yielded frank blood. She was optimized for full chemotherapy with COAP. However, the patient died of sepsis following 2 cycles of chemotherapy.

\section{Discussion}

Sickle cell disease has a worldwide spread but the impact is more in sub-Saharan Africa with about 3.6 million affected in Nigeria alone 9 . The prevalence of sickle cell disease in Nigeria ${ }^{10}$ is about $2 \%$. The life of patients with sickle cell anaemia is affected by recurrent vaso-occlusive and hyper-haemolytic crises with many requiring hospitalization and blood transfusion. The diagnosis of acute leukaemia in a patient with sickle cell disease portend a dismal days ahead, worse still in low income countries with limited resources for optimal management acute leukaemia. Of the 58 patients managed for acute leukaemia, five were also diagnosed with sickle cell disease. The most consistent presentation in all patients in this study was increasing requirement for blood transfusion in patients that had not been on routine drugs and have had poor clinic attendance. The drugs routinely administered to our patients with sickle cell disease include folic acid and paludrine. The drugs are meant to provide adequate folate for haemopoiesis and reduce the incidence and severity of malaria. In addition to supporting haemopoiesis, folic acid is also required in the maintenance of genomic integrity ${ }^{11}$.

Low folic acid has been associated with increased leukaemia risk ${ }^{1}$. Low folic acid makes cells vulnerable to mutagenesis. Lack of folic acid can affect the genetic and epigenetic integrity of $\mathrm{p} 53$, which is a well-characterized tumour suppressor ${ }^{12}$. In folic acid replete, ${ }^{5,10}$-Methylenetetrahydrofolate derived from folic acid ingestion donates a methyl group to uracil, converting it to thymine, which is used for DNA synthesis and repair. If folate is limited, imbalances in the DNA precursor pool occur, and uracil may be misincorporated into DNA. Subsequent misincorporation and defect in repair may lead to double strand breaks, chromosomal damage and cancer. Another mechanism is related to epigenetic effects, where folate deficiency reduces the availability of methyl donors, such as S-adenosylmethionine. This can lead to hypomethylation, which can cause genetic instability or cause protooncogene activation if the hypomethylation exists in the promoter region of a gene ${ }^{13}$.
This raises the question of the role of folic acid in reducing the risk of haematological malignancy in SCD patients who have increased requirement for folic acid due to increase bone marow activity consequent to the inherent haemolytic process. Unfortunately, the level of folic acid was not measured in these patients. Another suggestion for the aetiopathogeneis is a role for high cellular turnover (bone marrow in this instance) and chronic inflammation which occur in both SCD and leukemic pathogenesis ${ }^{4}$

The diagnosis of acute leukaemia in the patients was not made by the managing physicians who were managing the patients for primary sickle cell disease complications. This may be because the diagnosis of sickle cell disease confounded the presentation of acute leukaemia. The eventual referral of all the patients from a primary physician to the haematologist who reviewed the peripheral blood film of the patient underscores the role of the haematologist in the management of patients with sickle cell disease and the importance blood film review. The clinical feature of acute leukaemia could be masked by the frequent morbidity pattern in SCD. The resultant complications of the lifelong anaemia and vaso-occlusion in patients with sickle haemoglobin may preoccupy the attention of the managing physician so as to discountenance the possibility of the presence of other disorders in these patients thereby leading to missed diagnosis.

The observation that five sickle cell disease patients were diagnosed with acute leukemia over a seven years period corroborates the report that acute leukaemia may not be rare in patients with $\mathrm{SCD}^{4}$. The median age of 15 years in our patients is lower than 35.5 years from a study in United State which suggest that aetiology of the malignancy in patients in this study may not be similar. ${ }^{8}$. Two patients of the 4 cases reported had previously been on hydroxyurea. All the cases had similar cytogenetic abnormalities. Potential aetiologies in the report were therapy related and disease related chronic inflammation. There are concerns that hydroxyurea increases the risk of developing a malignancy such as leukemia. There was also a case report of a SCD developing AML after 50 months of hydroxyurea treatment ${ }^{14}$. None of our patients was on hydroxyurea neither had they ever had hydroxyurea suggesting that the increased risk of leukemia in the patients is not related to hydroxyurea. However, it is important to continue monitoring the side effects and toxicities of hydroxyurea in SCD patients. 
The predominance of AML subtype among these patients is in support of suggestion of increased risk for AML among SCD patients and previous studies done in the same hospital which showed that AML was commoner than ALL ${ }^{5,15}$. The predominance of AML among the patients may be attributed to the age distribution of the patients in which AML rather than ALL is commoner. Interestingly, the biochemical parameters were relatively normal except for one patient with deranged liver function tests, however the hyperleukocytosis in the patients was indicative of poor prognosis ${ }^{16}$ and is an oncological emergency. Acute leukaemia compounding the complications of SCD might have increased the challenges faced by the patients and care givers which contribute to the discharge against medical advice by the patients.

The unavailability of flow cytometry, genetic and molecular studies to further outline the nature of the acute leukaemia is a limitation to this study. Despite the dependence on morphology only to make the diagnosis, the bone marrow aspiration review that should complement the peripheral film review was not available in two of the patients. The diagnoses were sustained on the basis of florid blasts on the peripheral film, anaemia and thrombocytopenia. The management and outcome in the patients were further challenged by inability of the patients to get optimal management due to unavailability of funds to complete investigations. Even when investigation was available in the hospital and, unavailability of bone marrow transplantation in patients who entered remission was a limitation.

\section{Conclusion}

In view of the huge burden of the diagnosis of acute leukaemia in SCD patients on patients and care giver, a social support system, effective health insurance and prompt diagnosis should be available to improve survival.There is an enormous challenge in the management of these patients with acute leukaemia compounded by SCD. There is therefore, also a need for epidemiologic and cytogenetic studies to define the relationship between acute leukaemia and sickle cell disease.

\section{Conflict of interest}

None declared.

\section{References}

1. Natarjan K, Kutlar A. Disorders of Haemoglobin structure: Sickle cell diseases and related disorders.
Williams hematology. Ed Beutler E, Litchman MA, Coller BS, Kipps TJ, Seligsohn URI, 9 ${ }^{\text {th }}$ ed Mc GrawHill, NY. 2016:759-788

2. Singh BP, Singh A, Dhruw V, Benn AR. Chronic Myelogenous Leukemia in a Patient of Sickle Cell Anaemia: A Rare Case Report. Int J Sci Stud 2015;2(12):218219.).

3. Seminog OO, Ogunlaja OI, Yeates D, Goldacre MJ. Risk of individual malignant neoplasms in patients with sickle cell disease: English National Record Linkage Study. J R Soc Med. 2016;109(8):303-309.)

4. Brunson A, Keegan TH, Bang H, Mahajan A, Paulukonis S, Wun T. (2017). Increased risk of leukemia among sickle cell disease patients in California. Blood, 130(13), 1597-1599. Accessed April 18, 2019. https:// doi.org/10.1182/blood-2017-05-783233.)

5. SimaChauhani, Santosh Kumar Swain, Mahesh Chandra Sahu. (2018). Incidence of Haematological malignancies in Sickle Cell Patients from an Indian Tertiary Care Teaching Hospital. Asian J Pharm Clin Res, 11(3): 205-209

6. Aworanti OW, Anyanwu-Yeiya C, Olaniyi JA (2017). Haematologic profile of Treatment Naïve Patients with Acute Leukaemia. J Oncol Res Ther, JONT138 Doi:10.29011/2574-710x.000038

7. Smith MT, Skibola CF, Allan JM, Morgan GJ. Causal models of leukaemia and lymphoma. LARC Sci Publ. 2004. 373-92. [Medline])

8. Yang Li, Jake Maule, Jadee L. Neff, Chad M. McCall, Sarah Rapisardo, Anand S. Lagoo, Lian-He Yang, Regina D. Crawford, Yue Zhao \& Endi Wang. Myeloid neoplasms in the setting of sickle cell disease: an intrinsic association with the underlying condition rather than a coincidence; report of 4 cases and review of the literatureModern Pathology (2019)https://doi. org/10.1038/s41379-019-0325-6

9. Piel FB, Patil AP, Howes RE, Nyangiri OA, Gething PW, Dewi M, et al. Global epidemiology of sickle haemoglobin in neonates: a contemporary geostatistical model-based map and population estimates. Lancet. 2013;381(9861):142-51.

10. Akinyanju OO. A profile of sickle cell disease in Nigeria. Annals of the New York Academy of Sciences. 1989; 565:126-36.

11. Folate deficiency as predisposing factor for childhood leukaemia: a review of the literature by Catia Daniela Cantarella, Denise Ragusa, Marco Giammanco, Sabrina Tosi. Genes Nutr. 2017; 12: 14. PubMed Published online 2017 Jun 2. doi: 10.1186/s12263-0170560-8 
12. Folate deficiency in rats induces DNA strand breaks and hypomethylation within the p53 tumor suppressor gene. Kim YI, Pogribny IP, Basnakian AG, Miller JW, Selhub J, James SJ, Mason JB. Am J Clin Nutr. 1997 Jan; 65(1):46-52.

13. Linabery A, Johnson K, Ross J. Childhood cancer incidence trends in association with US folic acid fortification (1986-2008). Pediatrics 2012;129(6):1125 PubMed -1133

14. Therapy-Related Acute Myelogenous Leukemia in a Hydroxyurea-Treated Patient With Sickle Cell Ane- mia James G. Taylor, VI, Deepika S. Darari, Irina Maric, Zachariah McIver, Diane C. Arthur Ann Intern Med. Author manuscript; available in PMC 2012 Nov 280

15. Olaniyi JA, Umar GK (2013) An audit of Acute Leukaemia at the University College Hospital Ibadan, Nigeria 2:649 doi:10.4172/scientificreports.649

16. Hyperleukocyticleukemias and leukostasis: a review of pathophysiology, clinical presentation and management. Porcu P, Cripe LD, Ng EW, Bhatia S, Danielson CM, Orazi A, McCarthy LJ. Leuk Lymphoma. 2000 Sep; 39(1-2):1-18. 